\title{
Combination of atorvastatin and fenofibrate altered androgenic activities of male rats
}

\begin{abstract}
Background and objective: Many drugs and chemical substances may induce sexual dysfunction and have a negative impact on male fertility. Lipid-lowering agents like statins and fibrates are usually recommended for cardiovascular diseases prevention. However, the combination of atorvastatin and fenofibrate is the subject of questions concerning their effect on androgenic activities in this study. This study was designed to evaluate the efficacy and toxicity of atorvastatin, fenofibrate, and their combination on sperm parameters, sexual hormones, and histopathology of the testis.

Methods: Twenty-four male rats were divided into four groups, each of six. The first group served as a control. The second, third, and fourth groups received atorvastatin, fenofibrate, and their combination, respectively. After 28 days, blood samples were collected for hormones and other parameters evaluations. Testis and epididymis were taken for histopathology studies and sperm parameters assessments.

Results: Fenofibrate showed a significant reduction in sperm viability and serum levels of luteinizing and estradiol hormones. The combination of both drugs significantly reduced the sperm count and viability in normal male rats. Both atorvastatin and its combination mildly changed the histological structures of the testis, reduced number of spermatozoa, and arrested spermatogenesis.

Conclusion: The findings from this prospective study suggested that there was no harmful effect of atorvastatin usage on conventional sperm parameters and sexual hormones. Fenofibrate usage was not adversely associated with sperm parameters other than sperm viability. The combination of atorvastatin and fenofibrate significantly reduced the sperm count and viability. No deleterious effects of the drugs were seen on the testosterone, which was the essential hormone for all stages of spermatogenesis, sperm production, maturation, and transport.
\end{abstract}

Keywords: Atorvastatin; Fenofibrate; Sperm parameters; Androgens activities; Sexual hormones.

\section{Introduction}

Many medical conditions like sexual dysfunction and infertility can be caused by the intake of chemical substances, such as antiandrogens, antihypertensive, antipsychotic, and cytotoxicagents. These drugs can directly or indirectly inhibit spermatogenesis, sperm, and testicular functions. ${ }^{1,2}$ In the male, medications can disrupt the function of the reproductive system by acting as endocrine disrupting chemicals in the hypothalamic-pituitarygonad axis. ${ }^{3}$ FSH plays an important role in spermatogenesis by stimulating the production of androgen-binding protein by Sertoli cells in testis leading to concentrating testosterone and initiating spermatogenesis. ${ }^{4,5}$ In mammals, the spermatogenesis occurs in the seminiferous tubules of the testis. Successful maintenance of spermatogenesis is the main factor for male fertility. The connection between drugs used for lowering blood cholesterol and sexual dysfunction has been controversial, and many clinical

${ }^{1}$ Department of Pharmacology, College of Medicine, Hawler Medical University, Erbil, I raq.

* Correspondence: sundus.2007@hotmail.com 
researchers have confirmed that statins inhibit the production of sex hormones like testosterone. Statins, cholesterol-lowering agents, have a high efficiency on the prevalence of cardiovascular mortality and morbidity rates comparing with other antilipidemic agents such as niacin, fibrates, and ezetimibe. ${ }^{6,7}$ Statins act by inhibiting 3-hydroxy-3-methyl-glutarylCoenzyme-A (HMG Co-A) reductase competitively, which is the rate-controlling enzyme in the synthesis of cholesterol. Statins also inhibit dolichol as well as coenzyme., ${ }^{8,9}$ Decreased Q10 alters sperm parameters; sperm motility, vitality, number of spermatozoa, and increases sperm pathology. ${ }^{10}$ Additionally, statins are expected to cause sexual dysfunction and lower androgens because statins block the production of the substrate required for the synthesis of androgens ${ }^{11}$ and affect the sperm parameters and the seminal fluids composition of healthy men. ${ }^{12}$ Atorvastatin has been used as a combination therapy with other cholesterol-lowering agents as fenofibrate. ${ }^{13}$ The combined therapy with fibrates and statins has been shown to be more effective in patients with combined hyperlipidemia than the administration of either drug alone. ${ }^{14}$ Fenofibrateis a fibric acid derivative which acts through binding to peroxisome proliferator-activated receptor $\alpha$ (PPAR $\alpha)$ nuclear receptors and activates it. ${ }^{15}$ The activation of this receptor results in decreased serum levels of low density lipoprotein (LDL), increased hepatic uptake and thus increased high density lipoprotein (HDL). In addition, fenofibrate reduces plasma C-reactive protein and fibrinogen. ${ }^{16}$ Single lipidlowering drugs may have very selective effects on different lipoproteins; thus, the need to use a combined therapy. The combination of fenofibrate and atorvastatin has never been investigated regarding their influences on the androgenic activity, fertility, and particularly on sperm count and viability. Therefore, this study was performed to evaluate the possible effects of fenofibrate and atorvastatin alone or their combination on the androgenic activity in normal rats.

\section{Methods}

\section{Animals}

Twenty-four healthy male albino rats weighing $350-400 \mathrm{~g}$ of equivalent age groups were used in the study. The animals were kept at the animal house of the College of Medicine, Hawler Medical University under hygienic conditions and controlled temperature of $18-25{ }^{\circ} \mathrm{C}$ with 12 hours' light and dark cycle. The rats were allowed free access to a solid pellet diet and water ad libitum throughout the study. This study was approved by the Research Ethics Committee from the College of Medicine at Hawler Medical University.

\section{Experimental Design}

This study was conducted from October 2017 to May 2018. Twenty-four rats were divided into four groups each of six. The first group served as a control. The second and third groups were given daily oral administration (PO) of atorvastatin $(2 \mathrm{mg} / \mathrm{kg})$ and fenofibrate $(30 \mathrm{mg} / \mathrm{kg})^{17-19}$ respectively for four weeks. The fourth group received the combination of both atorvastatin and fenofibrate(PO) for four weeks. The solution of the drugs was prepared daily by dissolving each tablet of both drugs in 10 milliliters $(\mathrm{ml})$ distilled water at room temperature and then was given orally to the rats using oral gavage feeding needle for rats. At the end of the treatment period, the rats were anesthetized with a combination of ketamine $(75 \mathrm{mg} / \mathrm{kg})$ and xylazine $(10 \mathrm{mg} /$ $\mathrm{kg})^{20}$ and blood samples were collected through cardiac puncture from each rat for hormones and other biochemical parameters. Testicular and epididymis were removed from the sacrificed rats to record weight of testis and epididymis, and sperm parameters were evaluated. Bodyweight was estimated before, and after four weeks from the administration of the drugs. Additionally, the histological study of testis was performed for both control and experimental groups for 
evaluation of tissue abnormalities.

\section{Sperm analyses}

\section{Sperm viability}

The left testis and epididymis were removed, weighed, and fatty tissue was clipped. The caudal epididymis was placed in a petri dish containing $5 \mathrm{ml}$ of normal saline and split with a surgical blade to open the duct to release its contents. A drop of sperm suspension was then placed on a clean glass slide and mixed with a drop of eosin-nigrosin solution. ${ }^{21}$ A thin smear was prepared and air-dried. The stained slides were then examined under the microscope with X100 magnification.

\section{Sperm Count}

The petri dish was stored in the refrigerator for 24 hours to let spermatozoa release and then was swirled to achieve a uniform sperm suspension. One $\mathrm{ml}$ from the suspension was transferred into a glass beaker and then was mixed with $7 \mathrm{ml}$ of normal saline. The sperm counting was carried out with the Neubauer chamber cell counting of the haemocytometer ${ }^{22}$ and total sperm concentration was calculated.

\section{Histology}

Testis of control and treated rats were removed, weighed, and fixed in $10 \%$ formalin $^{23}$ for histological processing. Biopsy sections were processed using the wax-embedding method and thereafter stained with hematoxylin and eosin and examined under the microscope for histological evaluation. Photomicrographs of the slide preparation were also taken.

\section{Statistical analysis}

The results were evaluated statistically by using the statistical package for the social sciences (version 23.0). All the data were expressed as mean \pm SD and SE. Comparisons between groups were made by using Duncan test. Paired t-test was used to compare mean weights of rats. Changes were considered statistically significant when $P$ value was of 0.05 or less.

\section{Results \\ Effects of Atorvastatin and Fenofibrate and their Combination on Sperm Parameters}

Administration of atorvastatin $(2 \mathrm{mg} / \mathrm{kg})$ and fenofibrate $(30 \mathrm{mg} / \mathrm{kg})$ to normal male rats for 28 days, resulted in a slight reduction of sperm count to $(12.93$ million $/ \mathrm{ml})$ and $(13.60 \mathrm{million} / \mathrm{ml})$ respectively when they were compared with the control group (18.43 million $/ \mathrm{ml})$. While, in rats treated with a combination of atorvastatin and fenofibrate, a significant reduction $(P<0.05)$ in the epididymal sperm count (10.10 million $/ \mathrm{ml}$ ) was observed as shown in Table 1. The treated rats with fenofibrate alone or its combination with atorvastatin also showed a significant decrease in sperm viability; (60.42 \%) and (60.67\%) respectively compared with the control group $(88.90 \%)$, while, sperm viability of rats administrated with atorvastatin only exhibited a slight and non-significant decrease in sperm viability $(71.50 \%)$ compared with the control group (88.90\%) (Table 1).

Table 1: Effects of atorvastatin, fenofibrate, and their combination on sperm counting and sperm viability in normal rats $(n=24)$.

\begin{tabular}{lcccc}
\hline Parameters & Control & Atorvastatin & Fenofibrate & Combination \\
\hline Sperm Count (Million/ml) & $18.43 \pm 0.86$ & $12.93 \pm 1.27$ & $13.60 \pm 1.42$ & $10.10 \pm 3.17$ \\
& $\mathrm{a}$ & $\mathrm{ab}$ & $\mathrm{ab}$ & $\mathrm{B}$ \\
Sperm Viability $(\%)$ & $88.90 \pm 1.12$ & $71.50 \pm 1.52$ & $60.42 \pm 2.20$ & $60.67 \pm 12.79$ \\
& $\mathrm{a}$ & $\mathrm{ab}$ & $\mathrm{b}$ & $\mathrm{B}$ \\
\hline
\end{tabular}

Different letters indicate the significance of the result $(P<0.05)$. 


\section{Effects of Atorvastatin and Fenofibrate \\ rats (Table 2).} and their Combination on Sex Hormones

Non significant differences $(P>0.05)$ were found between the mean serum level of $\mathrm{FSH}$ in rats received atorvastatin (2.10 \pm 0.39$)$, fenofibrate $(2.26 \pm 0.54)$, or their combination $(2.20 \pm 0.31)$ when they were compared to the control group $(1.75 \pm 0.06)$ as shown in Table 2 . The same non-significant result could be seen with the mean serum levels of prolactin, total, and free testosterone. Significant reduction of estradiol $(20.44 \pm 1.26)$ and $\mathrm{LH}$ $(2.81 \pm 0.09)$ levels were observed in rats treated with fenofibrate as compared with control (24.54 \pm 1.32$)$ and atorvastatin $(3.23 \pm 0.19)$ respectively. Administration of either atorvastatin alone or in combination with fenofibrate did not change the serum levels of $\mathrm{LH}$ and estradiolin normal
Effects of Atorvastatin and Fenofibrate and their Combination on Serum Enzymes

Compared to the control group $(121.17 \pm 6.60)$, the aspartate aminotransferase (AST) level in rats treated with a daily dose of $2 \mathrm{mg} / \mathrm{kg}$ atorvastatin was significantly increased (157.25 \pm 14.24$)$. Administration of either fenofibrate $(138.90 \pm 6.60)$ orits combination with atorvastatin(138.30 \pm 13.51$)$ were unable to change the serum level of AST significantly $(P<0.05)$ as compared with the control rats. The same results could be seen in the level of alkaline phosphatase compared with normal rats. Neither alanine aminotransferase (ALT) nor creatinekinase significantly changed in all the three groups of rats (Table 3$)$.

Table 2: Effects of atorvastatin, fenofibrate, and their combination on sex hormones in normal rats $(n=24)$.

\begin{tabular}{lcccc}
\hline Parameters & Control & Atorvastatin & Fenofibrate & Combination \\
\hline FSH $(\mathrm{mlU} / \mathrm{ml})$ & $1.75 \pm 0.06$ & $2.10 \pm 0.39$ & $2.26 \pm 0.54$ & $2.20 \pm 0.31$ \\
$\mathrm{LH}(\mathrm{mlU} / \mathrm{ml})$ & $3.14 \pm 0.19$ & $3.23 \pm 0.16$ & $2.81 \pm 0.09 *$ & $2.97 \pm 0.08$ \\
Prolactin $(\mathrm{ng} / \mathrm{ml})$ & $4.12 \pm 0.93$ & $2.97 \pm 0.50$ & $3.20 \pm 0.49$ & $3.46 \pm 0.24$ \\
Total Testosterone $(\mathrm{ng} / \mathrm{ml})$ & $1.80 \pm 0.65$ & $1.31 \pm 0.65$ & $2.01 \pm 0.85$ & $0.85 \pm 0.42$ \\
Free testosterone $(\mathrm{pg} / \mathrm{ml})$ & $6.83 \pm 2.86$ & $5.21 \pm 2.39$ & $6.90 \pm 3.10$ & $1.85 \pm 0.82$ \\
Estradiol $(\mathrm{pg} / \mathrm{ml})$ & $24.54 \pm 1.32$ & $22.04 \pm 0.94$ & $20.44 \pm 1.26 * *$ & $22.21 \pm 1.27$ \\
\hline
\end{tabular}

${ }^{*} P<0.05$ when compared to atorvastatin group ${ }^{* *} P<0.05$ when compared to Control group

Table 3: Effects of atorvastatin, fenofibrate, and their combination on serum enzymes in normal rats $(n=24)$.

\begin{tabular}{lcccc}
\hline Parameters & Control & Atorvastatin & Fenofibrate & Combination \\
\hline AST $(\mathrm{U} / \mathrm{L})$ & $121.17 \pm 6.60$ & $157.25 \pm 14.24$ & $138.90 \pm 6.60$ & $138.30 \pm 13.51$ \\
& $\mathrm{~A}$ & $\mathrm{~b}$ & $\mathrm{ab}$ & $\mathrm{ab}$ \\
ALT $(\mathrm{U} / \mathrm{L})$ & $43.17 \pm 3.58$ & $50.08 \pm 0.79$ & $53.00 \pm 3.65$ & $50.35 \pm 3.60$ \\
& $\mathrm{~A}$ & $\mathrm{a}$ & $\mathrm{a}$ & $\mathrm{a}$ \\
Alkaline Phosphatase & $156.70 \pm 20.29$ & $199.50 \pm 27.39$ & $342.16 \pm 45.74$ & $265.83 \pm 42.59$ \\
$(\mathrm{U} / \mathrm{L})$ & $\mathrm{A}$ & $\mathrm{a}$ & $\mathrm{b}$ & $\mathrm{ab}$ \\
Creatine Kinase & $533.02 \pm 95.84$ & $987.50 \pm 225.13$ & $565.33 \pm 89.82$ & $940.66 \pm 344.63$ \\
$(\mathrm{U} / \mathrm{L})$ & $\mathrm{A}$ & $\mathrm{a}$ & $\mathrm{a}$ & $\mathrm{a}$ \\
\hline
\end{tabular}


Effects of Atorvastatin and Fenofibrate and their Combination on Lipid Profile

As shown in Table 4, the administration of atorvastatin, fenofibrate and their combination for a period of 28 days, had no significant effects on serum levels of total cholesterol, TG, HDL-C, and LDL-C in normal rats compared with the rats in the control group.

Effects of Atorvastatin, Fenofibrate, and their Combination on Body Weight, Testis- and Epididymal Weights

As shown in Table 5, the mean body weight in rats received atorvastatin $(2 \mathrm{mg} / \mathrm{kg} /$ day) or fenofibrate( $30 \mathrm{mg} / \mathrm{kg} /$ day $)$
$(P=0.007)$ and $(P=0.003)$ respectively, were significantly higher than the bodyweight of the same rats before treatment. However, a combined administration of both atorvastatin and fenofibrate had no detectable effect $(P=0.305)$ on the body weight of the rats compared to non-treated rats, as shown in Table 5. Right testis and right caudal epididymal weights of control and rats received drugs are presented in Table 6 . Non significant differences $(P>0.05)$ were noted between control and experimental groups in their testis and caudal epididymal weights.

Table 4: Effects of atorvastatin, fenofibrate, and their combination on lipid profile in normal rats $(n=24)$.

\begin{tabular}{lcccc}
\hline Parameters & Control & Atorvastatin & Fenofibrate & Combination \\
\hline Cholesterol $(\mathrm{mg} / \mathrm{dl})$ & $42.66 \pm 3.30$ & $41.05 \pm 4.35$ & $51.25 \pm 6.54$ & $46.83 \pm 4.29$ \\
& $\mathrm{a}$ & $\mathrm{A}$ & $\mathrm{a}$ & $\mathrm{a}$ \\
$\mathrm{TG}(\mathrm{mg} / \mathrm{dl})$ & $43.16 \pm 6.08$ & $58.45 \pm 14.03$ & $62.92 \pm 4.98$ & $53.38 \pm 8.36$ \\
& $\mathrm{a}$ & $\mathrm{A}$ & $\mathrm{a}$ & $\mathrm{a}$ \\
$\mathrm{HDL}-\mathrm{C}(\mathrm{mg} / \mathrm{dl})$ & $31.33 \pm 1.28$ & $24.26 \pm 3.20$ & $31.82 \pm 4.89$ & $31.15 \pm 2.60$ \\
& $\mathrm{a}$ & $\mathrm{A}$ & $\mathrm{a}$ & $\mathrm{a}$ \\
$\mathrm{LDL}-\mathrm{C}(\mathrm{mg} / \mathrm{dl})$ & $10.00 \pm 1.46$ & $11.50 \pm 2.19$ & $10.66 \pm 3.95$ & $8.33 \pm 3.49$ \\
& $\mathrm{a}$ & $\mathrm{A}$ & $\mathrm{a}$ & $\mathrm{a}$ \\
\hline
\end{tabular}

The same letters indicate the non-significance of the result.

Table 5: The effects of atorvastatin, fenofibrate, and combination on the bodyweight of normal rats $(n=24)$.

\begin{tabular}{lccc}
\hline & Before treatment & After treatment & $\boldsymbol{P}$ value \\
\hline Atorvastatin & $303.3 \pm 22.1$ & $345.0 \pm 18.9$ & 0.007 \\
Fenofibrate & $339.2 \pm 20.7$ & $357.5 \pm 22.7$ & 0.003 \\
Combination & $370.8 \pm 11.2$ & $371.7 \pm 9.2$ & 0.305 \\
\hline
\end{tabular}

$P<0.05$ is significant.

Table 6: The effects of atorvastatin, fenofibrate, and combination on the testis and caudal epididymis of the treated rats in normal rats $(n=24)$.

\begin{tabular}{lcccc}
\hline Parameters & Control & Atorvastatin & Fenofibrate & Combination \\
\hline Weight of testis $(\mathrm{g})$ & $1.26 \pm 0.06$ & $1.27 \pm 0.04$ & $1.33 \pm 0.02$ & $1.13 \pm 0.12$ \\
& $\mathrm{a}$ & $\mathrm{a}$ & $\mathrm{a}$ & $\mathrm{a}$ \\
Weight of caudal epididymis $(\mathrm{g})$ & $0.29 \pm 0.03$ & $0.28 \pm 0.02$ & $0.25 \pm 0.02$ & $0.25 \pm 0.02$ \\
& $\mathrm{a}$ & $\mathrm{a}$ & $\mathrm{a}$ & $\mathrm{a}$ \\
\hline
\end{tabular}

The same letters indicate the non-significance of the result. 
Effects of Atorvastatin, Fenofibrate, and their Combination on the Histology of Testis

In the control group, transverse sections of testis showed normal histological appearance and normal size of Sertoli and Leydig cells. In addition, a normal histological finding of mature seminiferous tubules with complete spermatogenesis and presence of spermatozoa in most of the tubular lumen were observed (Figure 1A). The same results were found for rats treated with fenofibrate $(30 \mathrm{mg} / \mathrm{kg})$
(Figure 1B). Figure 1C and 1D show the transverse sections of rat's testis which received atorvastatin $(2 \mathrm{mg} / \mathrm{kg} /$ day $)$ and its combination with fenofibrate $(30 \mathrm{mg} /$ $\mathrm{kg} /$ day) respectively. Treatment with both atorvastatin and its combination with fenofibrate caused mild focal arrest in spermatogenesis and absence of spermatozoa in a few of the tubular lumen as compared with the control group. Sertoli cell proliferation in some seminiferous tubules can also be seen.

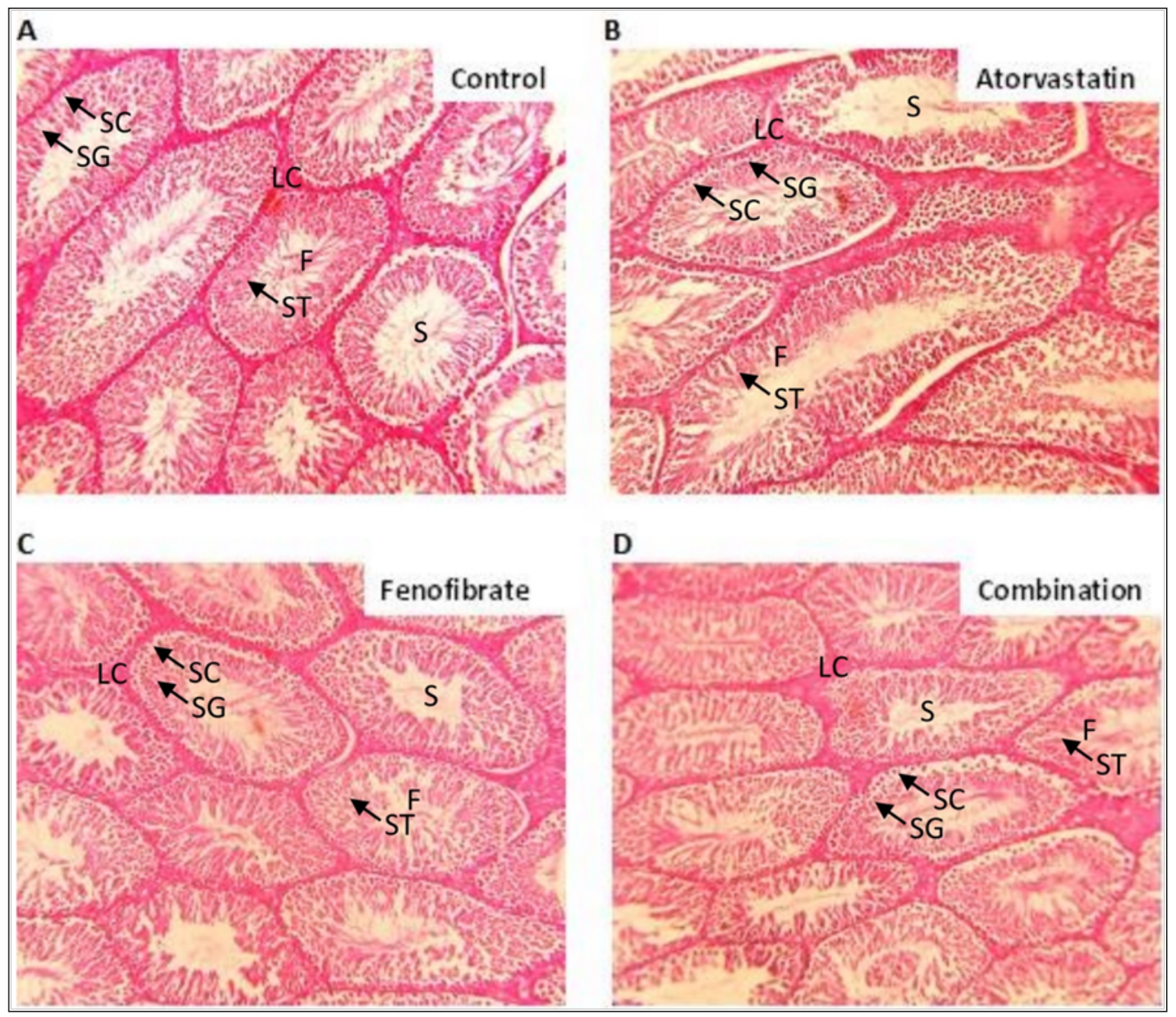

Figure 1: Histology of testis; (A) Control group where (B) Atorvastatin $2 \mathrm{mg} / \mathrm{kg}$, (C) Fenofibrate $30 \mathrm{mg} / \mathrm{kg}$, and (D) Combination of Atorvastatin and Fenofibrate, treated groups. H\&E stain. (F, Flagellae; LC, Leydig cell; SG, Spermatogonia; ST, Spermatid; SC, Sertoli cell)X40. 


\section{Discussion}

The present study was a prospective study, evaluating the efficacy and toxicity of anti-hyperlipidemic agents as atorvastatin, fenofibrate, and their combination on sperm parameters, serum enzymes, lipid profile, and sex hormones in healthy male albino rats. Effects of the combination of statins and fibrates on sperm parameters in animals with normal levels of cholesterol have never been studied before. In this study, the administration of atorvastatin $(2 \mathrm{mg} / \mathrm{kg} /$ day) and fenofibrate $(30 \mathrm{mg} / \mathrm{kg} /$ day) for a period of 28 days did not induce a significant reduction in sperm count in the normal rats as compared with rats in the control group. However, a combination of the two drugs could significantly affect the sperm count when they were compared with the control group. This might be due to the synergistic effect and pharmacokinetic interaction between these two drugs since fibrates could increase statin half-life and consequently augmenting statins side effects. ${ }^{24}$ In a recent study on healthy patients, the use of atorvastatin showed to be associated with long-term changes in sperm parameters. After five months of atorvastatin administration with a daily dose of $10 \mathrm{mg}$ and a withdrawal of the drug for three months, sperm count, morphology, and rate of acrosome reaction were reduced compared with samples before treatment. The authors concluded that atorvastatin intake by healthy and normocholesterolaemic subjects negatively affected sperm parameters and changed their seminal fluid composition. ${ }^{12}$ In contrast, other investigators performed a cohort study on men presenting an infertility clinic and underwent pharmacologic treatment with statins and compared to patients who did not take any medications. They did not find any drug-related deleterious effects of statin on conventional semen parameters. ${ }^{25}$ Oral administration of fenofibrate $(30 \mathrm{mg} / \mathrm{kg} /$ day) and its combination with atorvastatin ( $2 \mathrm{mg} / \mathrm{kg} /$ day) for 28 consecutive days (depending on a pilot study) resulted in a significant reduction in sperm viability as compared to control rats. Fenofibrate, a lipid-lowering agent, acts by binding to peroxisome proliferator-activated receptors (PPARa) which belong to the nuclear receptor super family and activates a specific transcription factor which regulates genetic expression of several enzymes involved in the metabolism of lipids. ${ }^{26}$ Activating of PPARa receptors induce testosterone esterification which results in erectile disorders. ${ }^{27}$ Studies have shown that PPARa agonists such as clofibrate and fenofibrate have various side effects such as suppression of spermatogenesis and erectile dysfunction via inhibition of enzymes involved in androgen synthesis. Therefore, chronic use of these drugs results in a reduction of sperm quality and infertility. ${ }^{28}$ In order to understand the relationship between sex hormones and infertility, estimation of $\mathrm{FSH}$, $\mathrm{LH}$, testosterone, prolactin, and estradiol were undertaken. Results from this study revealed that levels of sex hormones in groups treated with atorvastatin alone, and its combination with fenofibrate were not significantly changed $(P>0.05)$. Nevertheless, in fenofibrate treated group, the level of $\mathrm{LH}$ and estradiol were decreased significantly as compared to atorvastatin and control groups respectively. This findingmight be related to the negative feedback mechanism of testosterone. ${ }^{29}$ Serum levels of ALT and AST have for several decades been as markers of liver injury including fatty liver and are strong predictors for several diseases including coronary heart disease, atherothrombotic risk profile, and type 2 diabetes. ${ }^{30}$ Our study on liver enzymes revealed that non significant changes could be detected in the level of ALT enzyme between control and treated groups over a period of 28 days. Whereas, the oral administration of atorvastatin $(2 \mathrm{mg} / \mathrm{kg}$ ) for the same period significantly increased the AST enzyme level $(P<0.05)$. Studies showed that approximately $3 \%$ of patients treated with statins for a long period 
develop high elevation of the transaminase. ${ }^{31}$ In addition, the data of this study showed that serum alkaline phosphate was only increased significantly in the rats that received fenofibrate with a daily dose of $30 \mathrm{mg} / \mathrm{kg}$. This result was not in accordance with other studies, which reported a reduction in serum alkaline phosphatase and other liver enzymes like glutamyltranspeptidase activity. ${ }^{32}$ Furthermore, in this study, the effects of atorvastatin $(2 \mathrm{mg} / \mathrm{kg})$, fenofibrate $(30 \mathrm{mg} /$ $\mathrm{kg}$ ), and their combination given to healthy male rats for a period of 28 days showed non-significant changes in lipid profile. This could be related to the short duration of the intervention (28 days), which was inadequate to observe changes in the lipid profile. The finding of this study was in agreement with a result from a study by Yamagishi et al., which compared the effects of atorvastatin $(10 \mathrm{mg} / \mathrm{kg} /$ day $)$ with other statins over a four-week period and determined that statins have pleiotropic benefit effects that may be independent of their ability to lower the levels of cholesterol. ${ }^{33}$ The result of the current study on body weight showed that administration of atorvastatin $(2 \mathrm{mg} / \mathrm{kg})$ and fenofibrate $(30 \mathrm{mg} / \mathrm{kg})$ have significantly increased the bodyweight of the rats. It was hypothesized that this effect on the bodyweight might be due to the normal growth of the rats during the experiment period. This hypothesis was in agreement with a study done by Aguirre et al., which revealed that rats treated with atorvastatin for six weeks showed significantly large subcutaneous adipose tissue sizes with a percentage of $19 \%$. However, this change in subcutaneous adipose tissue was not accompanied by changes in final body weight. $^{34}$ Furthermore, several studies demonstrated that administration of fenofibrate alone effectively reduced body weight gain in both male and female, which was due to the effect of PPARa in the regulation of obesity. ${ }^{35}$ On the other hand, the combination of atorvastatin and fenofibrate could not show an increase in body weight in comparison to normal rats $(P<0.05)$. With regard to histological analysis, there was no change in the size of Sertoli and Leydig cells, seminiferous tubuli, and spermatogenesis in rats treated with fenofibrate $(30 \mathrm{mg} / \mathrm{kg}$ per day). While, in rats treated with either atorvastatin $(2 \mathrm{mg} / \mathrm{kg}$ per day) or its combination with fenofibrate, a mild arrest in spermatogenesis was seen with the absence of spermatozoa in few of the tubular lumen. In addition, the proliferation of Sertoli cells in some seminiferous tubules was also found. These changes of the histological structures of the test is were probably caused by the inhibition of HMG Co-A reductase by pathway, which leads to the reduction of Q10, an important intracellular antioxidant molecule. ${ }^{36}$ Thousands of patients around the world are using the combination of atorvastatin and fenofibrate for the treatment of hyperlipidemia. Therefore, the finding of this study will redound to the benefit of these patients who should be aware of the antiandrogenic effects of this combination. The selection of appropriate therapy is vital for preventing these deleterious side effects of anticholesterolemic drugs.

\section{Conclusion}

The findings from this prospective study suggested that there was no harmful effect of atorvastatin usage on conventional sperm parameters and sexual hormones. Fenofibrate usage was not adversely associated with sperm parameters other than sperm viability, while the combination of atorvastatin and fenofibrate significantly reduced the sperm count and viability. No deleterious effects of the drugs were seen on the testosterone, which is the essential hormone for all stages of spermatogenesis, sperm production, maturation, and transport.

\section{Competing interests}

The authors declare that they have no competing interests. 


\section{References}

1. Conaglen HM, Conaglen JV. Drug-induced sexual dysfunction in men and women. Australian prescriber 2013; 36(2):42-5.

2. Jung I, Gurzu S, Turdean S. Iatrogenic Pathology of the Male Genital System. Textbook of latrogenic Pathology. Bentham ebooks; 2017. P. 167-76.

3. Drobnis EZ, Nangia AK. Male reproductive functions disrupted by pharmacological agents. In: Impacts of Medications on Male Fertility. Adv Exp Med Biol 2017; 1034:13-24.

4. Schill WB, Comhaire FH, Hargreave TB. Andrology for the clinician. Berlin: Springer Science \& Business Media; 2006. P. 76.

5. Kraemer WJ, Rogol AD. The encyclopaedia of sports medicine: An IOC medical commission publication, the endocrine system in sports and exercise. Hoboken, USA: John Wiley \& Sons 2008; 11:86.

6. Antonopoulos A, Margaritis M, Lee R, Channon K, Antoniades C. Statins as anti-inflammatory agents in atherogenesis: molecular mechanisms and lessons from the recent clinical trials. Curr Pharm Des 2012; 18(11):1519-30.

7. Gotto AM, Moon JE. Recent clinical studies of the effects of lipid-modifying therapies. The Am J Cardio 2012; 110(1):15A-26.

8. Deichmann R, Lavie C, Andrews S. Coenzyme q10 and statin-induced mitochondrial dysfunction. Ochsner J 2010; 10(1):16-21.

9. Graveline D. Cholesterol-lowering injectables: more harm than good? Journal of American Physicians and Surgeons 2015; 20(4):119-22.

10. Ahmadi S, Bashiri R, Ghadiri-Anari A, Nadjarzadeh A. Antioxidant supplements and semen parameters: An evidence based review. Int J Reprod Biomed 2016; 14(12):729-36.

11. Schooling $\mathrm{CM}, \mathrm{Au}$ Yeung SL, Freeman G, Cowling BJ. The effect of statins on testosterone in men and women, a systematic review and meta-analysis of randomized controlled trials. BMC Medicine 2013; 11(1):57.

12. Pons-Rejraji $H$, Brugnon $F$, Sion $B$, Maqdasy $S$, Gouby G, Pereira B, et al. Evaluation of atorvastatin efficacy and toxicity on spermatozoa, accessory glands and gonadal hormones of healthy men: a pilot prospective clinical trial. Reprod Biol Endocrinol 2014; 12(1):65.

13. Koh KK, Quon MJ, Han SH, Chung WJ, Ahn JY, Seo $\mathrm{YH}$, et al. Additive beneficial effects of fenofibrate combined with atorvastatin in the treatment of combined hyperlipidemia. J Am Coll Cardiol 2005; 45(10):1649-53.

14. Amulya K, Gayathri K, Sowjanya G, Priyanka R, Ramesh G, Babu PS. A comparative study on atorvastatin plus fenofibratefor its safety and effectiveness in hyperlipidemic patients in as tertiary care teaching hospital. World J Pharm Res 2017; 6(10):1311-9.
15. Atanasovska E, Pavlovska K, Jakjovski K, Gjorgjievska K, Zendelovska D, Petrushevska M, et al. Differential effects of peroxisome proliferator-activator receptor (PPAR) alpha and gamma agonists on body weight and adipose depots in fructose Fed Wistarrats. Journal of Morphological Sciences 2018; 1(1):62-72.

16. Rang HP, Dale MM, Ritte JM, Flower RJ, Henderson G. Atherosclerosis and lipoprotein metabolism. In: Rang HP, Dale MM (Editors), Rang and Dale's Pharmacology. ${ }^{\text {th }}$ ed. Edinburgh: Elsevier Churchill Livingstone; 2016. P. 290.

17. Dizaye K, Jarjees $H$. Effects of Omega-3 on lipid profile and haematological parameters in hyperlipidemic rats. Middle East Journal of Internal Medicine 2014; 7(3):34-40.

18. Dizaye KF, Chalaby LA. Hypolipidemic efficacy of TrigonellaFoenum seeds in comparison with Rosuvastatin and Fenofibrateinhyperlipidemic rats. Middle East Journal of Family Medicine 2015; 13(6):30-8.

19. Galhotra P, Prabhakar P, Meghwani $H$, Mohammed SA, Banerjee SK, Seth S, et al. Beneficial effects of fenofibratein pulmonary hypertension in rats. Mol Cell Biochem 2018; 449(1-2):185-94.

20. Nagahama H, Nakazaki M, Sasaki M, KataokaSasaki Y, Namioka T, Namioka A, et al. Preservation of interhemispheric cortical connections through corpus callosum following intravenous infusion of mesenchymal stem cells in a rat model of cerebral infarction. Brain Res 2018; 1695:37-44.

21. Shabanian S, Farahbod $F$, Rafieian $M$, Ganji $F$, Adib A. The effects of Vitamin $C$ on sperm quality parameters in laboratory rats following long- term exposure to cyclophosphamide. J Adv Pharm Technol Res 2017; 8(2):73-9.

22. Yucra S, Gasco M, Rubio J, Nieto J, Gonzales GF. Effect of different fractions from hydroalcoholic extract of Black Maca (Lepidiummeyenii) on testicular function in adult male rats. Fertil Steril 2008; 89(5):1461-7.

23. Ellenburg J, Drwiega J, Posey A, Goldberg M, Gordetsky J, Kolettis P. MP19-18 The use of formalin as a fixative for testicular biopsies. J Urol 2018; 199(4):250-1.

24. Tarantino N, Santoro F, De Gennaro L, Correale M, Guastafierro F, Gaglione A, et al. Fenofibrate/ simvastatin fixed-dose combination in the treatment of mixed dyslipidemia: safety, efficacy, and place in therapy. Vasc Health Risk Manag 2017; 13:29-41.

25. Keihani S, Martin C, Craig JR, Zhang C, Presson $A P$, Myers JB, et al. Semen parameters are unaffected by statin use in men evaluated for infertility. Andrologia 2018; 50(5):e12995.

26. Monsalve FA, Pyarasani RD, DelgadoLopez F, Moore-Carrasco R. Peroxisome proliferator-activated receptor targets for the 
treatment of metabolic diseases. Mediators of Inflammation 2013; 2013:1-18.

27. Semet $M$, Paci $M$, Saïas-Magnan J, Metzler-Guillemain C, Boissier R, Lejeune $H$, et al. The impact of drugs on male fertility: a review. Andrology 2017; 5(4):640-63.

28. Delashoub M, Ziaee M, Khorrami A, Banan-Khojasteh SM. Comparison of the Effects of Clofibrate and Silafibrate on sperm parameters quality and sex hormones in male rats. Urol $\mathrm{J}$ 2018; 15(2):38-43.

29. Schlatt S, Ehmcke J. Regulation of spermatogenesis: an evolutionary biologist's perspective. In Seminarsin cell \& developmental biology. Academic Press 2014; 29:2-16.

30. Sookoian S, Pirola CJ. Liver enzymes, metabolomics and genome-wide association studies: from systems biology to the personalized medicine. World J Gastroenterol: WJG 2015; 21(3):711-25.

31. Jose J. Statins and its hepatic effects: newer data, implications, and changing recommendations. J Pharm Bioallied Sci 2016; 8(1):23-8.

32. Tsimihodimos V, Miltiadous G, Daskalopoulou SS, Mikhailidis DP, Elisaf MS. Fenofibrate: metabolic and pleiotropic effects. Curr Vasc Pharmacol 2005; 3(1):87-98.

33. Yamagishi SI, Matsui T, Nakamura K. Atorvastatin and diabetic vascular complications. Curr Pharm Des 2006;12(12):1549-54.

34. Aguirre L, Hijona E, Macarulla MT, Gracia A, Larrechi I, Bujanda L, et al. Several statins increase body and liver fat accumulation in a model of metabolic syndrome. J Physiol Pharmacol 2013; 64(3):281-8.

35. Yoon M. PPAR in obesity: sex difference and estrogen involvement. PPAR research 2010; 2010.

36. Littarru GP, Langsjoen P. Coenzyme Q 10 and statins: biochemical and clinical implications. Mitochondrion 2007; 7:168-74. 